\title{
Seleção de isolados de estreptomicetos para controle de Ralstonia solanacearum em tomateiro(1)
}

\author{
Carlos Alberto Tuão Gava( ${ }^{(2)}$, João Carlos Pereira(†), Maria do Carmo Fernandes ${ }^{(3)}$ \\ e Maria Cristina Prata Neves ${ }^{(4)}$
}

\begin{abstract}
Resumo - Em condições tropicais, a murcha-bacteriana, causada por Ralstonia solanacearum, tem provocado danos severos à cultura do tomate (Lycopersicon esculentum Mill.), principalmente em condições de temperaturas acima de $25^{\circ} \mathrm{C}$, com umidade relativa elevada. Neste contexto, o controle biológico pode representar uma alternativa viável. Este trabalho teve como objetivo selecionar isolados de estreptomicetos para o controle de R. solanacearum em tomateiro. Entre os isolados avaliados verificaram-se diferenças na inibição do patógeno in vitro, tanto em relação à faixa de $\mathrm{pH}$ avaliada, quanto ao tempo de observação. Constataram-se, também, variações no estabelecimento dos isolados de estreptomicetos na rizosfera das plântulas e nas mudas preparadas para transplante, e os isolados SP164, SF232, SAc326 e SG384 apresentaram as densidades populacionais mais elevadas. O experimento conduzido em canteiros com solo infestado com $R$. solanacearum mostrou que as plantas tratadas com o isolado SG384 apresentaram melhor nível de controle, 48 dias após a semeadura, período no qual todas as testemunhas haviam morrido.
\end{abstract}

Termos para indexação: Lycopersicon esculentum, controle biológico, inoculação, rizosfera.

\section{Selection of streptomycetes isolates for the control of Ralstonia solanacearum in tomato plants}

\begin{abstract}
The bacterial wilt caused by Ralstonia solanacearum causes high damages in tomato (Lycopersicon esculentum Mill.) culture, mainly under temperature above $25^{\circ} \mathrm{C}$ and high relative humidity. Because conventional methods of control have shown low efficiency, biological control is a promising alternative. This work aimed to select isolates of streptomycetes for $R$. solanacearum control in tomato. Differences were found among the isolates in the in vitro inhibition of the pathogen either in time or $\mathrm{pH}$ range. The streptomycetes isolates grew differently in the rhizosphere of seedlings and plantlets of tomato. The isolates SP164, SF232, SAc326 and SG384 showed the highest population densities. In the experiment conducted in soil infested with $R$. solanacearum, plants treated with the isolate SG384 presented best control level 48 days after sowing, period after which all control plants were dead.
\end{abstract}

Index terms: Lycopersicon esculentum, biological control, inoculation, rhizosphere.

(1) Aceito para publicação em 14 de maio de 2002 .

Extraído da dissertação de mestrado do primeiro autor apresentada à Universidade Federal Rural do Rio de Janeiro, Seropédica, RJ.

(2) Embrapa-Centro de Pesquisa Agropecuária do Trópico SemiÁrido, Caixa Postal 23, CEP 56300-000 Petrolina, PE. E-mail: gava@cpatsa.embrapa.br

(3) Empresa de Pesquisa Agropecuária do Estado do Rio de Janeiro(CNPAB), Estação Experimental de Itaguaí, BR 465-RJ, km 47, CEP 23851-970 Seropédica, RJ. E-mail: mcarmo@pesagro.rj.gov.br

(4) Embrapa-Centro Nacional de Pesquisa Agrobiologia (CNPAB), Caixa Postal 74505, CEP 23851-970 Seropédica, RJ. E-mail: mcpneves@cnpab.embrapa.br

(†) Embrapa-CNPAB, In memorian.

\section{Introdução}

A murcha-bacteriana, causada por Ralstonia solanacearum, provoca danos à cultura do tomate (Lycopersicon esculentum Mill.), principalmente nas condições de temperatura acima de $25^{\circ} \mathrm{C}$, em solos úmidos e que tenham $\mathrm{pH}$ abaixo de 7,0 (Lopes \& Santos, 1994). As medidas de controle normalmente recomendadas para fitobacterioses referem-se às tentativas de impedir a infestação das bactérias nos campos de cultivo ou de modificar o seu ambiente, tornando-o inóspito ao patógeno (Galli, 1980). 
Várias tentativas de controle têm sido feitas para a redução do potencial de inóculo de $R$. solanacearum em campos de cultivo. O controle químico não tem mostrado efeitos satisfatórios, visto que este patógeno apresenta distribuição cosmopolita, e é autóctone na maioria das áreas cultivadas (Agrios, 1974). O controle pela prática de rotação de culturas tem apresentado efeito reduzido, devido à capacidade de $R$. solanacearum de sobreviver tanto em hospedeiros alternativos como no solo, por longos períodos (Moura et al., 1998). A seleção de cultivares resistentes à murcha-bacteriana tem apresentado resultados melhores, porém inconsistentes. Temse observado que os insucessos desta prática se devem à grande diversidade genética do patógeno associada com as influências das condições ambientais. $\mathrm{O}$ controle biológico pela introdução de microrganismos antagônicos a $R$. solanacearum, incluindo-se estirpes avirulentas, pode não resultar no controle do fitopatógeno. Por outro lado, a utilização de isolados de estreptomicetos tem apresentado resultados mais promissores (El- Abyad et al., 1993).

As populações de actinomicetos são componentes importantes da comunidade microbiana da rizosfera, visto que podem influenciar o desenvolvimento das plantas e proteger as raízes contra patógenos. Actinomicetos em geral, e estreptomicetos em particular, têm sido avaliados como agentes de controle biológico, principalmente por serem reconhecidamente capazes de interagir com as plantas superiores ou mesmo com outras populações microbianas, mediante a produção de antibióticos (Gava et al., 1999; Pereira et al., 1999a, 1999b; Pereira, 2000; Pereira et al., 2000). Tem-se observado que algumas espécies de estreptomicetos apresentam capacidade de proteção, em diferentes plantas, a diversos patógenos oriundos do solo, tanto em experimentos em condições controladas quanto no campo (El-Abyad et al., 1993; Yuan \& Crawford, 1995; Moura et al., 1998).

Neste trabalho foi avaliada a influência da inoculação de isolados de estreptomicetos sobre Ralstonia solanacearum, visando ao controle biológico da murcha-bacteriana em tomateiro.

\section{Material e Métodos}

Sementes de tomate da variedade Santa Cruz Kada foram submetidas à inoculação dos isolados de estreptomicetos: SA63 (Streptomyces ansochromogenes),
SB122 (Streptomyces baarnensis), SP164 (Streptomyces pneumonicus), SF232 (Streptomyces flavovirens), SAc326 (Streptomyces achromogenes) e SG384 (Streptomyces griseus), pertencentes à coleção de culturas bacterianas da Embrapa-Centro Nacional de Pesquisa de Agrobiologia e que apresentaram antagonismo in vitro a Ralstonia solanacearum (Gava et al., 1999).

As inoculações foram feitas mediante suspensões de esporos em solução salina $(\mathrm{NaCl} 0,85 \%)$ contendo Tween 20 a $0,05 \%$. Estas suspensões foram obtidas a partir de placas de Petri com colônias dos isolados crescidas previamente por cinco a sete dias em meio de cultura descrito por Waksman (1961), e raspadas com auxílio de uma espátula. Em seguida, os esporos foram lavados em solução salina e armazenados em solução de glicerol $10 \%$ a $-25^{\circ} \mathrm{C}$ (Wellington \& Williams, 1978).

A avaliação da faixa de $\mathrm{pH}$ ideal tanto para crescimento dos estreptomicetos como para a inibição de $R$. solanacearum foi feita em placas de Petri contendo o meio Waksman ajustado para os valores de $\mathrm{pH} 4,5 ; 5,3$; 5,$7 ; 6,5 ; 7,0 ; 7,5$ e 8,0 , incubadas por cinco dias em temperatura de $30^{\circ} \mathrm{C}$. Como padrões utilizaram-se os resultados obtidos em meio de cultura com $\mathrm{pH} 7$.

A atividade antagônica dos isolados foi avaliada conforme Pereira et al. (1999a), e as colônias de estreptomicetos foram cobertas com $10 \mathrm{~mL}$ do meio $\mathrm{NB}$ (Difco), liquefeito à temperatura em torno de $40^{\circ} \mathrm{C}$, ao qual se acrescentou previamente uma suspensão contendo células de $R$. solanacearum com densidade aproximada de $10^{5}$ células $/ \mathrm{mL}$ de meio de cultura. A presença ou ausência dos halos de inibição foi avaliada em 24 e 72 horas de incubação.

Para avaliar a colonização da rizosfera do tomateiro pelos estreptomicetos, utilizaram-se sementes desinfestadas segundo Babadoost et al. (1996). A semeadura foi feita em substrato contendo uma mistura de areia, vermiculita, solo e vermicomposto, em proporções iguais, esterilizado em autoclave a $121^{\circ} \mathrm{C}$ por $30 \mathrm{mi}-$ nutos, distribuído em recipientes de $25 \mathrm{~g}$. Os isolados de estreptomicetos foram inoculados de forma a se obter a densidade aproximada de $10^{4}$ UFC (Unidades Formadoras de Colônias)/g de substrato. Após alcançarem o primeiro folíolo definitivo, as plântulas foram transferidas para vasos contendo $200 \mathrm{~g}$ do mesmo substrato, e colhidas 15 dias após.

O material rizosférico, substrato que permaneceu aderido às raízes após agitação manual (Cheng et al., 1996; Gava et al., 1999), foi extraído da agitação das raízes, em agitador orbital a $150 \mathrm{rpm}$ por 15 minutos, em erlenmeyers de $250 \mathrm{~mL}$ contendo $90 \mathrm{~mL}$ de solução salina $(\mathrm{NaCl}, 0,85 \%)$ e $10 \mathrm{~mL}$ de solução extratora contendo polietileno glicol 2,5\% e deoxicolato de sódio $0,1 \%$ (Herron \& Wellington, 1990). As suspensões obtidas sofreram diluições decimais seriadas, e $100 \mathrm{~mL}$ das diluições $10^{-3}, 10^{-4}$ 
e $10^{-5}$ foram transferidos para placas de Petri contendo meio Waksman e espalhados superficialmente com auxílio de uma alça de Drigalski. Após cinco dias de incubação a $30^{\circ} \mathrm{C}$, fez-se a contagem do número de UFC.

Para avaliar o controle da murcha-bacteriana por estreptomicetos em tomateiro cultivado em canteiros, infestados por $R$. solanacearum, as sementes de tomate foram semeadas em bandejas de plástico contendo substrato esterilizado constituído de uma mistura de areia e vermiculita (1:1). Com o desenvolvimento máximo do primeiro folíolo, as mudas foram transferidas para recipientes de plástico (copos descartáveis de $30 \mathrm{~mL}$ ) contendo $200 \mathrm{~g}$ de substrato esterilizado composto em proporções iguais por uma mistura de areia, vermicomposto e horizonte superficial de um solo Podzólico Vermelho-Amarelo, série Itaguaí. Os substratos previamente autoclavados a $120^{\circ} \mathrm{C}$ por 30 min receberam suspensões de estreptomicetos, de modo a apresentar $10^{4}$ UFC dos isolados/g de substrato. Utilizou-se também um tratamento-controle, sem inoculação de estreptomicetos. Quinze dias após, as mudas foram transplantadas para canteiros infestados por $R$. solanacearum (mantidos pela Pesagro-RJ, Estação Experimental de Seropédica), em um delineamento experimental de blocos ao acaso, com 15 mudas por tratamento, distribuídas aleatoriamente nos três canteiros.

As plantas irrigadas diariamente foram observadas quanto à exibição de sinais de murcha-bacteriana. Após o terceiro dia consecutivo de exibição de sintomas, as plantas foram colhidas, procedendo-se ao teste de exsudação, para confirmação da doença. Aos 48 dias, as plantas remanescentes foram colhidas e avaliadas quanto à infecção do patógeno, pelo teste de exsudação bacteriana em gota, ao microscópio (Galli, 1980; Lopes \& Santos, 1994).

\section{Resultados e Discussão}

A influência do pH do meio, no crescimento dos estreptomicetos e na ação antagônica sobre
Ralstonia solanacearum é apresentada na Tabela 1. Observa-se que os estreptomicetos cresceram em uma ampla faixa de $\mathrm{pH}$, variando de 4,5 a 8,0, e os isolados SA63, SP232 e SG384 cresceram nas condições mais ácidas, em valores de $\mathrm{pH}$ de 4,5, 5,3 e 4,5, respectivamente.

As bactérias são sensíveis às concentrações mais elevadas de $\mathrm{H}^{+}$no ambiente (Drozdowicz, 1991). Entretanto, em solos ácidos do cerrado brasileiro, tem-se observado que as densidades médias das populações dos actinomicetos variam de $1,7 \times 10^{4}$ a $50,1 \times 10^{4} \mathrm{UFC} / \mathrm{g}$ de solo seco (Pereira et al., 1999b). A ocorrência de actinomicetos ácido-tolerantes e acidofílicos pode estar relacionada com as condições ambientais nos solos dos quais foram isolados. Assim, estas características estariam na dependência da presença de nichos ecológicos, onde ocorrem reduções acentuadas de $\mathrm{pH}$, principalmente em face das atividades metabólicas das populações na comunidade microbiana (Drozdowicz, 1991).

Em 72 horas de incubação, os estreptomicetos produziram metabólitos capazes de inibir o crescimento de $R$. solanacearum in vitro em $\mathrm{pH}$ que variou de 4,5 (isolado SG384) a 8,0 (isolados SA63, SB122 e SAc326), e o isolado SP164 apresentou ação antagônica somente em pH 6,5 e 7,5. Além disso, houve diferenças nos tamanhos dos halos de inibição com a variação do $\mathrm{pH}$. A ação antagônica dos isolados de estreptomicetos e a variação no tamanho dos halos de inibição, provavelmente estão associadas às alterações qualitativas e/ou quantitativas dos metabólitos antibióticos produzidos, resultantes das influências diferenciadas do $\mathrm{pH}$ do meio de cultura.

A intensidade de inibição do crescimento de $R$. solanacearum por metabólitos produzidos pelos

Tabela 1. Faixa de pH do meio de cultura em que ocorreu crescimento e antagonismo a Ralstonia solanacearum de isolados de Streptomyces spp. e intensidade de inibição de $R$. solanacearum em pH 7,0.

\begin{tabular}{|c|c|c|c|c|}
\hline \multirow[t]{2}{*}{ Isolados de estreptomicetos } & \multirow[t]{2}{*}{ Crescimento } & \multirow[t]{2}{*}{ Antagonismo a $R$. solanacearum } & \multicolumn{2}{|c|}{$\begin{array}{c}\text { Intensidade de inibição }^{(1)} \\
\text { Horas de incubação }\end{array}$} \\
\hline & & & 24 & 72 \\
\hline SA63 S. ansochromogenes & $4,5-8,0$ & $5,7-8,0$ & +++ & +++ \\
\hline SB122 S. baarnensis & $5,7-8,0$ & $5,7-8,0$ & ++ & ++ \\
\hline SP164 S. pneumonicus & $6,5-8,0$ & $6,5-7,5$ & ++ & + \\
\hline SF232 S. flavovirens & $5,3-8,0$ & $5,7-7,5$ & ++ & + \\
\hline SAc326 S. achromogenes & $6,5-8,0$ & $6,5-8,0$ & +++ & ++ \\
\hline SG384 S. griseus & $4,5-8,0$ & $4,5-7,5$ & +++ & +++ \\
\hline
\end{tabular}

+++: inibição forte de crescimento de $R$. solanacearum (halos com diâmetro superior a $30 \mathrm{~mm}$ ); ++: inibição moderada de crescimento (halos inferiores a $30 \mathrm{~mm}$ ); +: inibição fraca (diâmetro inferior a $6 \mathrm{~mm}$ ). 
isolados de estreptomicetos em $\mathrm{pH}$ 7,0 foi variável. Em 24 horas de incubação a presença dos isolados SA63, SAc326 e SG384 resultou em halos de inibição do crescimento do fitopatógeno com diâmetros superiores a $30 \mathrm{~mm}$, e nos isolados SA63 e SG384, a intensidade deste efeito também foi observada em 72 horas de incubação. No período de 24 horas, os isolados SB122, SP164 e SF232 inibiram moderadamente o crescimento de $R$. solanacearum (halos inferiores a $30 \mathrm{~mm}$ ), e em 72 horas o isolado SB122 continuou apresentando antagonismo na mesma intensidade, enquanto os isolados SP164 e SF232 passaram a apresentar inibição fraca ao crescimento do fitopatógeno (halos com diâmetros inferiores a $6 \mathrm{~mm}$ ).

As variações em relação aos diâmetros dos halos de inibição em pH 7,0 podem estar associadas com a produção de diferentes metabólitos inibidores pelos isolados de estreptomicetos. A ação dos antibióticos sobre a célula bacteriana pode estar relacionada com interferências na estrutura e função da parede ou da membrana celular, ou com a inibição de um processo metabólico interno (Tavares, 1982). As variações nos halos de inibição também podem estar relacionadas com as diferenças nas difusões dos metabólitos inibidores do crescimento de $R$. solanacearum em meio de cultura, como foi constatado anteriormente por Crawford et al. (1993).

Além disso, observou-se, a partir das 48 horas, a presença de colônias de bactérias dentro dos halos de inibição, o que evidencia a resistência das células de $R$. solanacearum aos metabólitos produzidos. Isto provavelmente ocorreu devido às concentrações destes metabólitos no meio de cultura, que inibiu mas não foi capaz de impedir o crescimento de todas as células nas populações de $R$. solanacearum. A resistência adquirida geralmente resulta em modificações das características fisiológicas e/ou metabólicas quando se observam as células das quais se originaram (Lovato et al., 1991; Pereira et al., 1991). Desta forma, houve uma seleção de células com resistência natural aos metabólitos produzidos, que podem apresentar crescimento mais lento que as demais (Pereira, 1983).

Têm-se observado que a capacidade de produzir antibióticos in vitro é comum entre os microrganismos isolados dos solos (Drozdowicz, 1991). Entretanto, nem sempre há boa correlação entre os resultados in vitro e in vivo, o que pode colocar em dúvi- da o papel ecológico dos metabólitos produzidos (Williams, 1982; Williams \& Vickers, 1986). Desta forma, o aparecimento de colônias de $R$. solanacearum resistentes aos metabólitos produzidos pelos isolados de estreptomicetos, conforme observado em placas, pode trazer como consequiência prática a variabilidade no controle da murcha-bacteriana no tomateiro.

No substrato de produção de mudas, as densidades das populações de estreptomicetos apresentaram variações significativas (Tabela 2). As densidades médias variaram de $1,72 \times 10^{4} \mathrm{a}$ $38,70 \times 10^{4} \mathrm{UFC} / \mathrm{g}$ de substrato seco, quando o substrato foi inoculado com os isolados SA63 e SP164, respectivamente. Estas densidades são similares às encontradas anteriormente, em condições ambientais diferenciadas (Gava et al., 1999; Pereira et al., 1999a, 1999b, 2000).

Na rizosfera do tomateiro, os números médios de UFC dos isolados/g de raiz seca também apresentaram variações significativas, e as densidades das populações oriundas de hifas foram superiores aos das populações provenientes de esporos. A única exceção foi o isolado SA63, que apresentou densidade de $1,58 \times 10^{3} \mathrm{UFC} / \mathrm{g}$ de raiz seca, tanto nas populações oriundas de hifas como nas de esporos. Efeitos diferenciados sobre as populações de actinomicetos originárias de hifas e esporos têm sido observados (Pereira et al., 1999b, 2000), geralmente associados aos fatores ambientais, que determinam modificações morfológicas nas estruturas das hifas e dos esporos. Desta forma, a relação hifas/esporos pode estar associada principalmente ao $\mathrm{pH}$ do solo (Gray \& Williams, 1975), à disponibilidade de nutrientes no solo (Wellington et al., 1990) ou ao efeito

Tabela 2. Densidades das populações de estreptomicetos (Streptomyces spp.) no substrato esterilizado de produção de mudas e na rizosfera das plântulas de tomateiro, aos 15 dias após o transplante de mudas produzidas em substrato inoculado com $\operatorname{esporos}^{(1)}$.

\begin{tabular}{|c|c|c|c|}
\hline \multirow[t]{2}{*}{ Estreptomicetos } & \multirow{2}{*}{$\begin{array}{c}\text { Substrato } \\
\text { Total } \\
\left(\mathrm{UFCx} 10^{4} / \mathrm{g}\right)\end{array}$} & \multicolumn{2}{|c|}{ Rizosfera } \\
\hline & & $\begin{array}{l}\text { Hifas } \\
\left(\mathrm{UFC} \times 10^{3} / \mathrm{g}\right.\end{array}$ & $\begin{array}{r}\text { Esporos } \\
\text { de raízes) }\end{array}$ \\
\hline SA63 S. ansochromogenes & $1,72 \mathrm{c}$ & $1,58 b$ & $1,58 \mathrm{~b}$ \\
\hline SB122 S. baarnensis & $3,24 \mathrm{c}$ & $3,98 \mathrm{~b}$ & $1,26 \mathrm{~b}$ \\
\hline SP164 S. pneumonicus & $38,70 \mathrm{a}$ & $200,00 \mathrm{a}$ & $50,10 \mathrm{a}$ \\
\hline SF232 S. flavovirens & $36,22 \mathrm{a}$ & $158,00 \mathrm{a}$ & $126,00 \mathrm{a}$ \\
\hline SAc326 S. achromogenes & $19,63 b$ & $200,00 \mathrm{a}$ & $100,00 \mathrm{a}$ \\
\hline SG384 S. griseus & $14,46 b$ & $79,40 \mathrm{a}$ & $39,80 \mathrm{a}$ \\
\hline
\end{tabular}

${ }^{(1)}$ Em cada coluna, médias seguidas pela mesma letra não diferem entre si pelo teste de Tukey a $5 \%$ de probabilidade. 
rizosférico (Drozdowicz, 1991; Bolton Junior et al., 1993).

Densidades mais elevadas das populações oriundas de hifas evidenciam que a rizosfera do tomateiro proporcionou condições adequadas para o desenvolvimento das populações de estreptomicetos. A maior produção de células vegetativas seria uma conseqüência deste fato, considerando-se que os esporos são estruturas de resistência, e sua produção é predominante em condições ambientais desfavoráveis (Kalakoutskii \& Agre, 1973; Vobis,1997).

A superioridade numérica das populações oriundas da fração hifas não resultou em incremento das populações de estreptomicetos na rizosfera do tomateiro, visto que, de modo geral, essas populações foram semelhantes às densidades das populações encontradas no substrato. As únicas exceções foram os isolados SA63 e SB122, cujas densidades foram inferiores.

A colonização rizosférica é determinada pela interação de uma série de fatores que variam de acordo com as plantas, os microrganismos e o ambiente. Têm-se observado densidades mais elevadas de estreptomicetos na rizosfera de milho, ervilha, algodão, rabanete, cenoura, tomate e pimentão (Yuan \& Crawford, 1995; Gava et al., 1999). Por outro lado, na rizosfera da soja as populações de actinomicetos oriundas de hifas e de esporos não foram estimuladas (Pereira et al., 1999a).

Assim, é possível que a variação nas densidades dos estreptomicetos na rizosfera do tomate seja determinada pelo padrão de exsudatos radiculares, associado com as diferentes exigências nutricionais e com outros fatores de crescimento específicos, exigidos pelos isolados (Cheng et al., 1996).

As densidades das populações de estreptomicetos oriundas de hifas e esporos na rizosfera do tomateiro, no momento de transplante das plantas para o infectário,

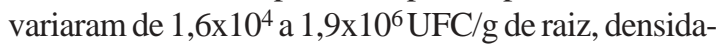
des, estas, semelhantes às das populações de actinomicetos encontradas em diversas condições ambientais (Pereira et al., 1999a, 1999b, 2000).

Os primeiros sintomas de murcha-bacteriana surgiram 10 dias após o transplante para canteiros infestados com $R$. solanacearum (Figura 1). Inicialmente, as plantas sem inoculação e as que receberam inoculação dos isolados SP164, SF232 e SAc326 apresentaram sintomas da doença.

As plantas que receberam os isolados SA63 e SB122 começaram a apresentar os sintomas da murcha-bacteriana somente 18 dias após o transplante. A inoculação de SB122 resultou, aos 20 dias, em $13 \%$ das plantas com os sintomas da doença. No $25^{\circ}$ dia, a freqüência média foi de $23 \%$, evoluindo para $50 \%$ no 28 o dia. Aos 48 dias após o transplante, a freqüência de infecção foi semelhante à dos demais tratamentos.

Nas plantas submetidas à inoculação do isolado SG384, até o 20o dia após o transplante, a freqüência de infecção por $R$. solanacearum foi zero, e aos 48 dias, somente $36 \%$ apresentaram sintomas da murcha-bacteriana. A maior eficiência no controle da murcha-bacteriana apresentada por este isolado pode estar associada principalmente com a sua capacidade de crescer e inibir fortemente o crescimento do patógeno em uma faixa de $\mathrm{pH}$ mais ampla (Tabela 1), visto que as suas densidades no substrato de mu-

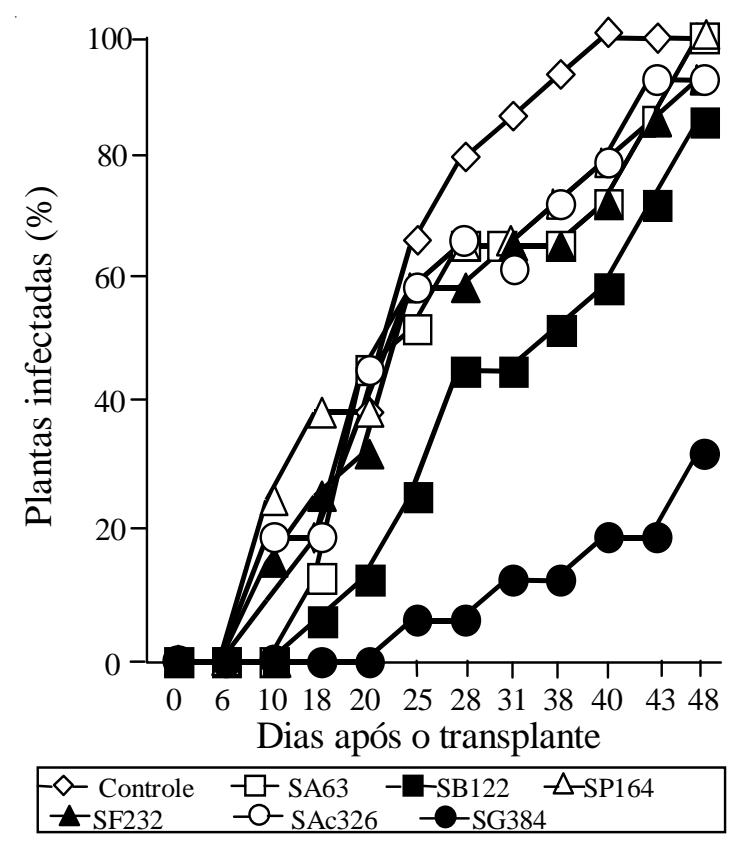

Figura 1. Frequiências médias de mudas de tomateiro variedade Santa Cruz Kada, com sintomas de murchabacteriana, obtidas em substrato inoculado com isolados de estreptomicetos e transplantadas para canteiros com infestação de Ralstonia solanacearum. 
das e na rizosfera das plântulas de tomateiro não foram as mais elevadas (Tabela 2).

As variabilidades na freqüência das plantas infectadas demonstram que a inoculação dos estreptomicetos resultaram em um controle diferenciado da infecção das mudas de tomateiro pelo patógeno. A frequiência de infecção pode estar associada com a densidade inicial do inóculo dos isolados de estreptomicetos, ou com as relações entre os crescimentos do isolado utilizado e das raízes do tomateiro. Estes resultados também podem ser decorrentes da capacidade dos isolados de produzir metabólitos antibióticos a $R$. solanacearum. A maior ou menor capacidade de produzir estes metabólitos pode estar associada com as modificações no equilíbrio estabelecido entre as populações microbianas na rizosfera, decorrentes principalmente de alterações do $\mathrm{pH}$, da umidade, da aeração, da temperatura e da disponibilidade de nutrientes orgânicos e inorgânicos, pelo efeito isolado ou do somatório de dois ou mais fatores (Madsen, 1995).

A produção de antibióticos no solo como mecanismo de antagonismo pode ter efeito limitado. Como geralmente são produtos do metabolismo secundário, sua produção pode ficar limitada a nichos onde ocorrem fontes de nutrientes adequadas, como, por exemplo, matéria orgânica parcialmente degradada. Estes antibióticos também poderão ser adsorvidos pelos colóides minerais e orgânicos do solo, limitando ainda mais sua atividade (Pereira, 1995). Além da produção de antibióticos, as populações de actinomicetos apresentam outros mecanismos de antagonismo, que podem envolver parasitismo, indução de autólise, produção de outras substâncias tóxicas ou inibidores voláteis e, ainda, inibidores de atividade enzimática (Cardoso, 1978).

Além do isolado SG384, que apresentou maior potencial no controle da murcha-bacteriana no tomateiro, as avaliações das ações destes fatores atuando isoladamente ou em conjunto tornam-se de importância fundamental e devem ser estendidas a outros isolados de actinomicetos que inicialmente apresentaram antagonismo in vitro, visto que também podem ser determinantes do grau de eficiência das populações de actinomicetos introduzidas para fins de controle biológico.

\section{Conclusões}

1. As inoculações dos isolados de estreptomicetos resultam em variações no controle da murcha-bacteriana em tomateiro.

2. Existem diferenças na inibição do crescimento de Ralstonia solanacearum in vitro, tanto em relação à faixa de pH quanto ao tempo de observação.

3. Na rizosfera das mudas de tomateiro preparadas para o transplante, as densidades das populações de estreptomicetos são variáveis, porém os isolados SP164, SF232, SAc326 SG384 apresentam densidades populacionais mais elevadas.

4. Em canteiros com solo infestado com Ralstonia solanacearum, o isolado SG384 apresenta melhor nível de controle, com apenas $35 \%$ de plantas infectadas no $48^{\circ}$ dia após o transplante; nos demais isolados, a porcentagem de infecção é superior a $80 \%$.

\section{Referências}

AGRIOS, G. N. Plant pathology. 3. ed. New York: Academic, 1974. 803 p.

BABADOOST, M.; DERIER, M. L.; GABRIELSON, R. L. Efficacy of sodium hypochlorite treatments for control of Xanthomonas campestris pv. campestris in Brassica seeds. Seed Science and Technology, Zurich, v. 24, p. 715, 1996.

BOLTON JUNIOR, H.; FREDICKSON, J. K.; ELLIOTT, L. F. Microbial ecology of the rhizosphere. In: METTING JUNIOR, F. B. (Ed.). Soil microbial ecology: applications in agricultural and environmental management. New York: M. Dekker, 1993. p. 27-63.

CARDOSO, E. J. B. N. Relações ecológicas entre microrganismos. In: GALLI, F. (Ed.). Manual de fitopatologia. 2. ed. São Paulo: Agronômica Ceres, 1978. v. 1, p. 26-51.

CHENG, W.; ZHANG, A.; COLEMAN, D. C.; CARROL, C. R.; HOFFMAN, C. A. Is available carbon limiting microbial respiration in the rhizosphere? Soil Biology and Biochemistry, Oxford, v. 28, n. 10/11, p. 1283-1288, 1996.

CRAWFORD, D. L.; LYNCH, J. M.; WHIPPS, J. M.; OUSLEY, M. A. Isolation and characterization of actinomycete antagonists of fungal root pathogen. Applied and Environmental Microbiology, Washington, v. 59, p. 3899-3905, 1993. 
DROZDOWICZ, A. G. Microbiologia ambiental. In: ROITMAN, I.; TRAVASSOS, I. R.; AZEVEDO, J. L. (Ed.). Tratado de microbiologia. Rio de Janeiro: Manole, 1991. v. 2, p. 1-102.

EL-ABYAD, M.; EL-SAYED, M. A.; EL-SHANSHOURY, A. R.; EL-SABAGH, S. M. Towards the biological control of fungal and bacterial diseases of tomato using antagonistic Streptomyces spp. Plant and Soil, The Hague, v. 149, p. 185-195, 1993.

GALLI, F. P. (Coord.). Manual de fitopatologia: doenças das plantas cultivadas. Piracicaba: Ceres, 1980. v. 2.

GAVA, C. A. T.; PEREIRA, J. C.; NEVES, M. C. P. Effects of streptomycetes inoculation on seed germination and plant growth in tomato. Anais da Academia Brasileira de Ciências, Rio de Janeiro, v. 71, p. 3-11, 1999.

GRAY, T. R. G.; WILliamS, S. T. Soil microorganisms. 2. ed. London: Longman, 1975. 240 p.

HERRON, P. R.; WELLINGTON, E. M. H. New method for extraction of streptomycete spores from soil and application to the study of lysogeny in sterile amended and nonsterile soil. Applied and Environmental Microbiology, Washington, v. 56, n. 5, p. 1406-1412, 1990.

KALAKOUTSKII, L. V.; AGRE, N. S. Endospore of actinomycetes: dormancy and germination. In: SYKES, G.; SKINNER, F. A. (Ed.). Actinomycetales: characteristics and practical importance. London: Academic, 1973. p. 179193.

LOPES, C. A.; SANTOS, J. R. M. dos. Doenças do tomateiro. Brasília: Embrapa-SPI/ Embrapa-CNPH, 1994. $67 \mathrm{p}$.

LOVATO, P. E.; PEREIRA, J. C.; VIDOR, C. Sobrevivência de Rhizobium leguminosarum bv. phaseoli em solo e sua relação com a ocorrência em nódulos e fixação de nitrogênio em feijoeiro. Revista Brasileira de Ciência do Solo, Campinas, v. 5, n. 3, p. 227-282, 1991.

MADSEN, E. L. Impacts of agricultural practices on subsurface microbial ecology. Advances in Agronomy, San Diego, v. 54, p. 1-67, 1995.

MOURA, A. B.; ROMEIRO, R.; NEVES, M. C. P. Bioensaio para avaliação massal de actinomicetos antagonistas a Ralstonia solanacearum, em tomateiro. Pesquisa
Agropecuária Brasileira, Brasília, v. 33, n. 12, p. 2065 2072, dez. 1998.

PEREIRA, J. C. Ecologia da comunidade bacteriana em solos de cerrados. 1995. $172 \mathrm{f}$. Tese (Doutorado) Universidade Federal Rural do Rio de Janeiro, Itaguaí.

PEREIRA, J. C. Interações entre as populações de actinomicetos e outros organismos na rizosfera. Seropédica: Embrapa-CNPAB, 2000. 14 p. (Documentos, 119).

PEREIRA, J. C. Obtenção e avaliação de mutantes de Rhizobium phaseoli resistentes a antibióticos e fungicidas. 1983. 88 f. Dissertação (Mestrado) - Universidade Federal do Rio Grande do Sul, Porto Alegre.

PEREIRA, J. C.; NEVES, M. C. P.; DROZDOWICZ, A. Dinâmica das populações bacterianas em solos de cerrados. Pesquisa Agropecuária Brasileira, Brasília, v. 34, n. 5, p. 801-811, maio 1999a.

PEREIRA, J. C.; NEVES, M. C. P.; DROZDOWICZ, A. Influência da antibiose exercida por actinomicetos às estirpes de Bradyrhizobium spp., na nodulação da soja. Pesquisa Agropecuária Brasileira, Brasília, v. 34, n. 1, p. 99108, jan. 1999b.

PEREIRA, J. C.; NEVES, M. C. P.; GAVA, C. A. T. Efeito do cultivo da soja na dinâmica da população bacteriana, em solos de cerrado. Pesquisa Agropecuária Brasileira, Brasília, v. 34, n. 6, p. 1183-1190, jun. 2000.

PEREIRA, J. C.; VIDOR, C.; LOVATO, P. E.; PENTEADO, A. F. Simbiose entre feijão e estirpes de Rhizobium leguminosarum bv. phaseoli, sensíveis e resistentes a antibióticos e fungicidas. Pesquisa Agropecuária Brasileira, Brasília, v. 26, n. 7, p. 1097-1105, jul. 1991.

TAVARES, W. Manual de antibióticos para estudante de medicina. Rio de Janeiro: Atheneu, 1982. 374 p.

VOBIS, G. Morphology of actinomycetes. In: MIYADOH, S. (Ed.). Atlas of actinomycetes. Asakura: Society for Actinomycetes, 1997. p. 180-191.

WAKSMAN, S. A. The actinomycetes: classification, identification and descriptions of genera and species. Baltimore: Williams \& Wilkins, 1961.260 p.

WELLINGTON, E. M. H.; CRESSWELL, N.; SAUNDERS, V. A. Growth and survival of streptomycete inoculants and extent of plasmid transfer in sterile and 
nonsterile soil. Applied and Environmental Microbiology, Washington, v. 56, n. 5, p. 1413-1419, 1990.

WELLINGTON, E. M. H.; WILLIAMS, S. T. Preservation of actinomycete inoculum in frozen glycerol. Microbios Letters, Cambridge, Inglaterra, v. 6, p. 151-157, 1978.

WILLIAMS, S. T. Are antibiotics produced in soil? Pedobiologia, Jena, v. 23, p. 427-435, 1982.
WILLIAMS, S. T.; VICKERS, J. C. The ecology of antibiotic production. Microbial Ecology, New York, v. 12, p. 43-52, 1986.

YUAN, W. M.; CRAWFORD, D. L. Characterization of Streptomyces lydicus WYEC108 as a potential biocontrol agent against fungal root and seed rots. Applied and Environmental Microbiology, Washington, v. 61, n. 8, p. 3119-3128, 1995. 